\title{
Time Error in Project Management: A Case Study in Yanbu, Saudi Arabia
}

\author{
Umar Ammar Altahtooh \\ Correspondence: Umar Ammar Altahtooh, Taibah University, Yanbu, Saudi Arabia
}

\author{
Received: November 30, 2015 Accepted: December 16, 2015 Online Published: January 4, 2016 \\ doi:10.11114/bms.v2i1.1277 \\ URL: http://dx.doi.org/10.11114/bms.v2i1.1277
}

\begin{abstract}
Time error is a reality in the majority of projects. This paper presents empirical research which investigates the influence of time error during project life cycle. Data were collected using interviews with project managers and analyzed using content analysis. The findings explore the causes of time error in projects in Yanbu, Saudi Arabia. This study gives an introductory insight into the influence of time error. It finds that time error affects the triple constraints of project management.
\end{abstract}

Keywords: project, Saudi Arabia, time error

\section{Introduction}

Saudi Arabia is one of the richest countries in the Gulf Cooperation Council (GCC). It has invested a lot of money in projects in Yanbu, which is an industrial city and a petroleum shipping site by the Red Sea. Most of these projects have overrun in terms of timescale. This paper is exploratory and qualitative in nature, and the case study data were collected through interviews. The aim of the study is to provide an overall perspective on the impact of time error on projects by exploring the following question:

- What is the influence of time error on projects?

According to Altahtooh and Emsley (2014), time error can happen throughout the project execution phase. In order to answer the above question, the researcher gathered data from interviews. Then, a content analysis was used to analyze the data from 13 project managers.

The next section of the paper gives an overview of project life cycle and time management. Following this, the research method is described, and then the results are discussed. Finally, the findings are summarized.

\section{Literature Review}

It is not easy to conduct a literature review of time error because it is still a new concept in the project management field. However, time error can occur during project life cycle and time management.

\subsection{Project Life Cycle}

One of the most important elements of project life cycle is time. Thus, the definition of 'project' is mainly centered around time. According to PMBOK ${ }^{\circledR}$ Guide (Project Management Institute, 2008), a project is "a temporary endeavor undertaken to create a unique product, service or result" (p.5). "Temporary" means a project has a definite beginning and a definite end. Project life is constrained by "a fixed schedule" (Ramakrishnan, 2009). Regarding construction, project life cycle means "the period spanning from project formulation to construction completion" (Gransberg, 1999, p.9). In project management, it is defined as a collection of project phases (Project Management Institute, 2008). There are four phases of project life cycle:
1. initiating
2. planning
3. executing
4. closing

According to Boyde (2015), there are two standard project life cycles:

- Linear/Waterfall Model (Figure 1) 


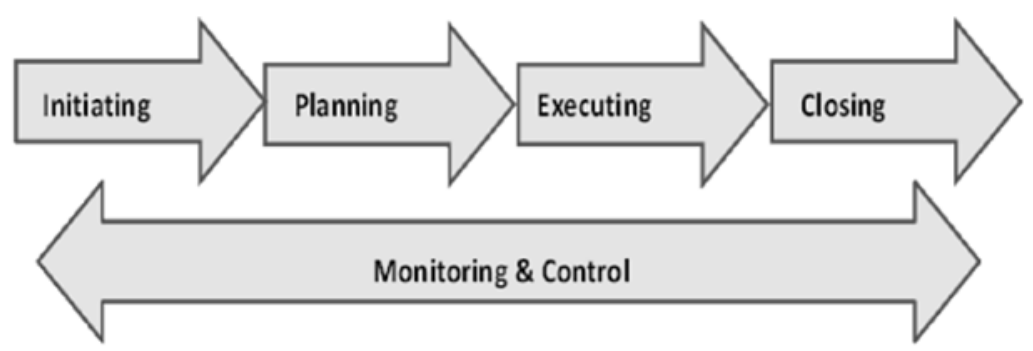

Figure 1. Waterfall Model (Source: Boyde, 2015)

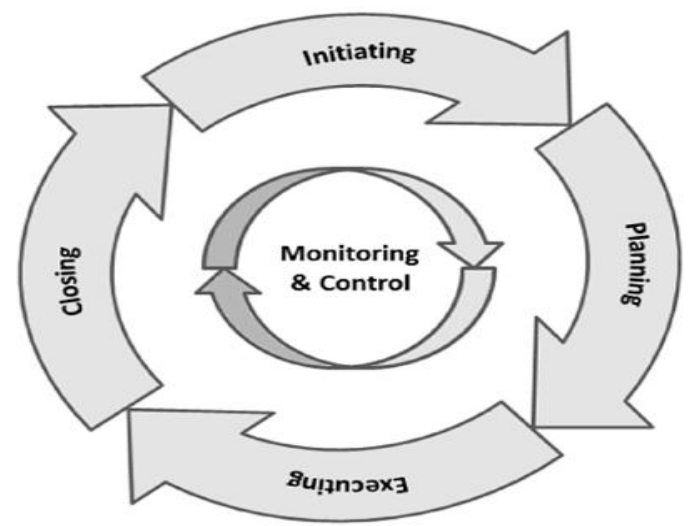

Figure 2. Agile Modelling (Source: Boyde, 2015)

The Waterfall Model is a linear process that moves from one phase to the next while Agile Modelling is an iterative process. Simply, a project life cycle is described as project phases relative to time. Thus, time management is required in project management.

\subsection{Time Management}

The guide of PMBOK has a chapter about time management which is related to:

- Defining the activities

- Sequencing the activities

- Estimating the activities resources

- Estimating the duration of the activities

- Developing the schedule

- Controlling the schedule

The above six elements are related to "Activities Chain Management" or "Activities Management", but it is named "Time Management". This indicates the importance of time in project life cycle. Time is the first element of the triple constraints, so time management is not easy for the project team, and indeed it is a very challenging task. Altahtooh and Emsley (2014) introduce some terms that are related to time management:

- Accepted Time Project Delay

- Accepted Time Project Advance

- Time Error Project Correction

- Authorized Project Duration

- Actual Project Duration

Time error is the difference between the actual project duration and the authorized project duration. This term is recently developed by Altahtooh and Emsley to determine the outcomes of a project.

\section{Method}

The aim of interviewing project managers was to collect rich qualitative data about the influence of time error on projects. The interviews were conducted with 13 project managers in Yanbu, Saudi Arabia. In this qualitative case study, 
data were collected through structured interviews. A pilot study was done to test the reliability of the interview questions and the feasibility of the case study. The goal of conducting the pilot study was to improve the questions so that they were clear and concise. None of the interview questions required the disclosure of confidential information.

The project managers were interviewed for between 50 and 60 minutes between 7th July and 12th August 2015. The interviews were carried out in their offices. To overcome any form of constraints in this case study, each participant was asked the same questions. With the prior consent of the interviewee, the structured interviews were recorded and transcribed. The Arabic interviews were transcribed and translated into English.

Thus, the outcomes of these interviews examined using as content analysis and presented in the form of themes by identifying the most frequent responses and analyzing narrative data to explore the influence of time error on projects as described below.

\section{Results}

Content analysis is used for exploratory and explanatory research; however, it is most often used in descriptive research (Neuman, 1997). Qualitative content analysis is defined as "the systematic and objective procedure used to identify and analyze significant written, verbal or visual data in order to tabulate, classify, summarize and compare the contents" (Seamen, 1987). The transcripts were analyzed using content analysis to answer the research question. The design of the data analysis process is as follows: a) analysis, b) interpretation, c) synthesis, d) documentation (Ptacek, 2009).

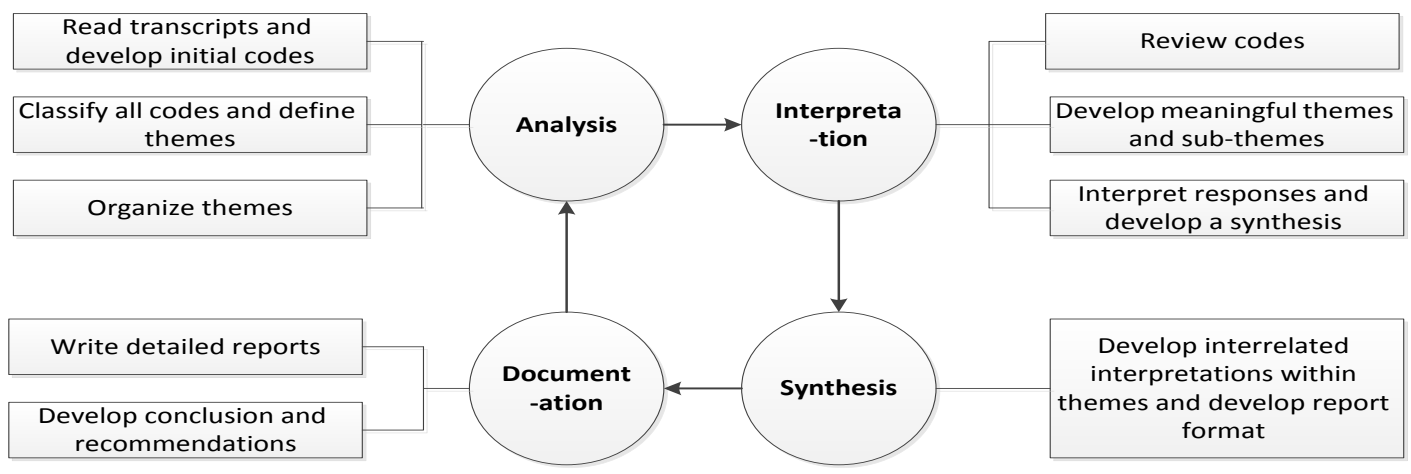

Figure 3. Data Analysis Process (Adapted from: Ptacek, 2009)

\subsection{Profile of Project Managers}

In terms of nationality, four of the project managers were Saudi while nine were non-Saudi. As seen in Table 1, eight of the interviewees were in their forties while five were in their thirties. Eleven of the participants in the interview sample had completed a bachelor's degree, while two had completed a master's degree. In terms of industrial field, four of the participants were from the construction field, three were from the petrochemical field, three were from government, two were from the IT industrial field and one was from the telecommunication field. Two of the project managers had more than 10 years' experience in supervising projects, eight had between 5 and 10 years' experience and three had less than 5 years' experience. The range of the number of projects that the interviewees had been involved in as a project manager was between one and six.

Table 1. Project Managers' Profiles

\begin{tabular}{ccccccc}
\hline $\begin{array}{c}\text { Project } \\
\text { Manager }\end{array}$ & Nationality & Age & $\begin{array}{c}\text { Education } \\
\text { Level }\end{array}$ & Industrial Field & $\begin{array}{c}\text { Number of Years' } \\
\text { Experience in the Field }\end{array}$ & $\begin{array}{c}\text { Number of Projects } \\
\text { as PM }\end{array}$ \\
\hline PM01 & Non-Saudi & 47 & Bachelor & Construction (C) & 11 & 5 \\
PM02 & Non-Saudi & 42 & Master & Petrochemical (P) & 8 & 4 \\
PM03 & Saudi & 40 & Bachelor & Petrochemical (P) & 8 & 3 \\
PM04 & Non-Saudi & 38 & Bachelor & Construction (C) & 4 & 2 \\
PM05 & Non-Saudi & 44 & Bachelor & Construction (C) & 8 & 7 \\
PM06 & Non-Saudi & 39 & Bachelor & Telecommunication (T) & 13 & 4 \\
PM07 & Non-Saudi & 48 & Bachelor & Petrochemical (P) & 4 & \\
PM08 & Saudi & 35 & Bachelor & IT (IT) & 3 & 4 \\
PM09 & Saudi & 31 & Bachelor & Government (G) & 8 & 4 \\
PM10 & Saudi & 40 & Master & Government (G) & 9 & 4 \\
PM11 & Non-Saudi & 43 & Bachelor & Construction (C) & 5 & 4 \\
PM12 & Non-Saudi & 38 & Bachelor & IT (IT) & 9 & 4 \\
PM13 & Non-Saudi & 49 & Bachelor & Construction (C) & \\
\hline
\end{tabular}




\subsection{Time Error in Project Management}

In this section of the analysis, the interview questions were asked in order to explore time error in projects from the perspective of project managers, focusing on the following aspects:

- definition of time error in project management

- causes of time error in project management

- influence of time error on projects

The next section shows the responses of participants to all of the above elements regarding time error.

\subsubsection{Definition of Time Error}

This study seeks to introduce a practical definition of time error in project management. The researcher asked the participants - as the first question of the interview - the following: What is time error in project management?

The aim of the above question is to understand the nature of time error according to the explanations given by the project managers. The following answers show their understanding in different ways about time error in project management.

Nine project managers believe that time error leads to a project delay, as shown in the following answers:

"I'm not familiar with this term [time error] but I think it is a type of delay" PM03.

"Let me say this time error is definitely real in projects, and it is somehow related to delay" PM09.

"It [time error] is a delay time that can happen during a project life cycle" PM01.

"It's an interesting question; let me say that the sum of time errors during a project life cycle leads to a delay in project management" PM10.

"I don't use this term [time error] very often. For me it [time error] means a delay in project schedules" PM11.

"I believe that time error is a delay in project completion time" PM07.

"I think any delay in project work can be defined as time error in project management" PM13.

"Time error is a delay in project delivery" PM04.

"I think any mistake in project schedule means delay or time error" PM05.

According to the above answers, this group of project managers has a general view about time error in project management which is related to delay time in project completion. They represent about $69.2 \%$ of the interview sample in Yanbu, Saudi Arabia. Delay is the keyword which is used to define time error in project management by these project managers.

Four project managers think that time error is an uncertainty that may contribute to project schedule problems, as shown in the following responses:

"I think time error is an uncertainty factor which cannot be estimated due to many reasons" PM02.

"I think no one can give an accurate definition for time error in project management, but it [time error] can occur if there is an uncertainty during the decision-making process" PM06.

"I can define time error as an issue of uncertainty in project time management" PM12.

"Time error is a result of trying to eliminate or reduce an uncertainty in project planning" PM08.

Regarding the above responses, this group of project managers links time error with uncertainty in project management. They represent about $30.8 \%$ of the interview sample. Uncertainty is the primary factor in defining time error according to this group. In this section, a common definition of time error is introduced by project managers. The next section presents the causes of time error in project management.

\subsubsection{Causes of Time Error in Project Management}

It is important to identify the causes of time error before discovering its influence on projects. The next interview question for the project managers was: What are the causes of time error in project management?

The answers were analyzed to explore the causes of time error. The replies can be classified into two categories: 1) time error due to managerial factors and 2) time error due to technical factors.

Table 2 summarizes the causes of time error identified by the project managers in Yanbu, Saudi Arabia. 
Table 2. Causes of Time Errors

\begin{tabular}{|c|c|c|c|c|}
\hline No & Causes of Time Error & Managerial & Technical & Industrial Field \\
\hline 1 & Lowest bid wins & $\bullet$ & & $(\mathrm{G}),(\mathrm{C})$ \\
\hline 2 & Changes in orders & • & & (C), (IT) \\
\hline 3 & Poor communication & $\bullet$ & & $(\mathrm{IT}),(\mathrm{G}),(\mathrm{C}),(\mathrm{P})$ \\
\hline 4 & Turnover & - & & $(\mathrm{IT}),(\mathrm{G})$ \\
\hline 5 & Shortage of labor & - & & $(\mathrm{C}),(\mathrm{P})$ \\
\hline 6 & New technology & & - & (P), (IT) \\
\hline 7 & Poor leadership & $\bullet$ & & $(\mathrm{C}),(\mathrm{G}),(\mathrm{P}),(\mathrm{IT})$ \\
\hline 8 & Conflict and friction between client and contractor & $\bullet$ & & $(\mathrm{C}),(\mathrm{P})$ \\
\hline 9 & Late payments to contractors & $\bullet$ & & $(\mathrm{G}),(\mathrm{C})$ \\
\hline 10 & Poor design & & $\bullet$ & $(\mathrm{C}),(\mathrm{G}),(\mathrm{P}),(\mathrm{IT})$ \\
\hline 11 & Unrealistic time schedules & & • & $(\mathrm{C}),(\mathrm{P}),(\mathrm{IT}),(\mathrm{G})$ \\
\hline 12 & Litigation issues & - & & (C), (G) \\
\hline 13 & Misunderstanding end-user requirements & $\bullet$ & & (IT) \\
\hline 14 & Wrong testing tools & & - & (P), (IT) \\
\hline 15 & Bad coding practices & & $\bullet$ & (IT) \\
\hline
\end{tabular}

As shown in Table 2, ten causes of time error in project management are managerial factors and five are technical factors. In this case study, four causes of time error (poor communication, poor leadership, poor design and unrealistic time schedules) occur in all industrial fields (C, G, P, IT). Two causes (misunderstanding end-user requirements and bad coding practices) are limited to the IT industry. Thus, identifying the causes of time error can help project managers to take precautions against them. The next section presents the influence of time error on projects.

\subsubsection{The Influence of Time Error}

In the above section, the causes of time error in project management are identified by 13 project managers in Yanbu, Saudi Arabia. The third interview question for the participants was: What is the greatest effect of time error on projects?

The aim of the above question is to determine the influence of time error on projects. In exploring the influence of time error, the answers of project managers focus on the following elements:

- schedule

- cost

- scope

These elements are the triple constraints of project management. The following replies show how time error can directly affect project schedule:

"I think that the greatest effect of time error on a project is the scheduled shift start time and end time of activities" PM08.

"If time error happens in project execution, this means a scheduled delivery time will be late" PM02.

"The effect of time error on the project includes time and cost overrun" PM12.

"Let me say that time error associated with poor time management leads to many schedule issues in the project" PM06.

"At all times the suppliers are responsible for providing raw materials on time, but in many cases they fail, and as a project manager, this case is an example of time error" PM03.

"I think that time error can happen because of unimportant meetings, and of course, those meetings may lead to schedule problems" PM05.

"The margin of time error varies from case to case in the project, but the sum of cases can affect project schedule based on the size of margin" PM01.

"I think that one time error after another during the project's life can have a negative effect on time management" PM07.

The following responses show how time error can affect project cost:

"So more time errors mean more faults in budget estimate" PM04.

"Also, I think that time error is costly for any project" PM10.

"The effect of time error on the project includes time and cost overrun" PM12.

"Sometimes a project manager does not care so much about time error, but project cost will need to be estimated again" PM09. 
According to the above responses, time error has a clear effect on: i) project schedule and ii) project cost. However, it has a clearer effect on schedule. Only one of the project managers mentioned the effect of time error on project scope.

The following response shows how time error can affect project scope:

"From my experience, any error of time causes a pressure on everyone and everything to do with the project, so in many cases project scope is affected by this time error" PM13.

The next section presents the discussion and conclusions.

\section{Discussion and Conclusions}

This study aims to investigate the influence of time error on projects in Yanbu, Saudi Arabia, as a case study. It makes a valuable contribution to the literature on time error in project management research. Indeed, this paper is the first attempt to empirically examine the influence of time error on project. Based on the definitions given by the project managers in section 3.2.1, time error is a new term in the project management field. The majority of project managers in the sample think that time error in project management is a cause that leads to delay while some think that it is a result due to an uncertainty. The next figure show the relationship of three terms: time error, delay and uncertainty.

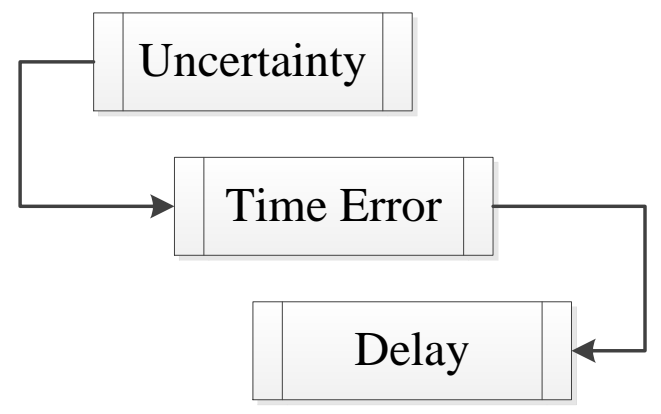

Figure 4. Definition of Time Error

As shown in Figure 4, it is clear that time error is not totally delay or uncertainty. Time error occurs after uncertainty and before delay. Thus, the justification of this definition is that when uncertainty leads to errors during project life cycle, time error occurs. However, this time error will be involved in two scenarios: a) undelayed project delivery when time error is solved and b) delayed project delivery when time error is unsolved. Also, uncertainty does not lead directly to delay.

The causes of time error are classified as follows:

a) managerial causes:

- lowest bid wins

- changes in orders

- poor communication

- turnover

- shortage of labor

- poor leadership

- conflict and friction between client and contractor

- late payments to contractors

- litigation issues

- misunderstanding end-user requirements

b) technical causes:

- new technology

- poor design

- unrealistic time schedules

- wrong testing tools

- bad coding practices

The influence of time error on projects can affect the following elements:

- schedule

- cost

- scope 
This paper adds more knowledge to the understanding of time error. No prior study has been undertaken on the effect of time error. Thus, in determining the effect of time error in project management in Yanbu, Saudi Arabia, this is an original study. It is very important that more research about time error in project management is carried out. It is significant to note that time error is a new concept in the field of project management. The limitation of this study is that the sample of project managers is small, but it presents an introduction so that academics can do further research on time error in project management.

\section{References}

Altahtooh, U., \& Emsley, M. (2014). Is a Challenged Project One of the Final Outcomes for an IT Project? System Sciences (HICSS), 2014 47th Hawaii International Conference on (pp. 4296-4304). IEEE. http://dx.doi.org/10.1109/hicss.2014.531

Boyde, J. (2012). A Down-To-Earth Guide To SDLC Project Management: Getting Your System/Software Development Life Cycle Project Successfully Across the Line Using Pmbok adaptively (2nd ed). Available at http://books.google.com

Gransberg, D. D. (1999). The Cost of Inaction: Does Massachusetts Need Public Construction Reform?. Pioneer Institute for Public Policy Research, Center for Restructuring Government, White Paper No. 7, Boston, Massachusetts.

Neuman, W. L. (1997). Social research methods: Qualitative and quantitative approaches. 3rd ed. Needham Heights, MA: Allyn and Bacon.

Project Management Institute. (2008). A Guide to the Project Management Body of Knowledge (PMBOK® Guide). 3rd ed. USA.

Ptacek, C. (2009). Using morphological content analysis to mine insights from qualitative interviews. Available at http://www.quirks.com/articles/2009/20090304.aspx

Ramakrishnan, S. (2009). Innovation and scaling up Agile software engineering projects, Issues in Informing Science and Technology, Volume 6, 557-574. http://iisit.org/Vol6/IISITv6p557-574Ramakrishnan573.pdf

Seamen C. H. C. (1987). Research Methods-Principles, Practice and Theory for Nursing. Norwalk, CT: Appleton and Lange.

\section{$(\mathrm{cc}) \mathrm{BY}$}

This work is licensed under a Creative Commons Attribution 3.0 License. 